\title{
Seismic Design of Steel Frames Equipped by Control Devices
}

\author{
Nikos G. Pnevmatikos, ${ }^{1, *}$ and George Hatzigeorgiou ${ }^{2}$
}

\author{
${ }^{1}$ Technological Educational Institution of Athens, Department of Civil Engineering, Surveying and Geoinformatics, \\ Ag. Spyridonos Str., P.O. 12210 Egaleo-Athens, Greece; ${ }^{2}$ Hellenic Open University, School of Science and Technology, \\ Parodos Aristotelous 18, GR-26335, Patras, Greece
}

\begin{abstract}
The design philosophy of EC8 is to ensure that in the event of the design earthquake, human lives are protected and no collapse will occur, while extended damages will be observed. This is achieved by ductility and capacity design. This design philosophy drives to an additional cost for repairing damage of structures. On the other hand, it is costly and uneconomic to design structures behaving in elastic range, especially under high level of earthquake excitation. An alternative direction to this strategy, which is examined in this paper, is to design a controlled structure capable to resist a design earthquake loads, remaining in elastic range and thus without damage. The idea behind this philosophy is that one portion of earthquake loading will be resisted by a control system while the rest will be resisted by the structure. The structure, initially, is analyzed and designed according to the current codes. The elastic and design earthquake forces are first calculated according to the elastic and the design spectrum. The required control forces are calculated as the difference between elastic and design forces. The maximum value of capacity of control devices is then compared with the required control force. If the capacity of the controlled devices is higher than the required control force then the control devices are accepted and installed to the structure. Then, the structure is designed according to the design forces. In the case where the maximum available control device capacity is lower than the demanded control force then an additional portion of control forces should be resisted by the building. In that case, an iterative procedure is proposed and a scale factor, $\alpha$, that reduces the elastic response spectrum to a new design spectrum, is calculated. The structure is redesigned based on the new design spectrum and then the devices are installed to the structure. The proposed procedure imposes that the controlled structure will behave elastically for the design earthquake and no damage will occur, consequently no additional repair cost will be needed. An initial cost of buying and installing the control devices is required. In order to ensure that the controlled structure behaves elastically, a dynamic control analysis with saturation and time delay control is performed. Following the proposed procedure the numerical results show that the structure remains in elastic and no damage occurs.
\end{abstract}

Keywords: Control device, earthquake engineering, response spectrum, seismic design, steel frame, structural control.

\section{INTRODUCTION}

Structural control systems fall into four basic categories: passive, active, semi-active and, hybrid control Soong [1], Soong and Spencer [2]. These structural control systems are presented in Figs. (1-5) below.

\section{Passive Control}

Passive control structures can be either conventional structures where the energy is dissipated in specific locations on structural elements, so that failure mode control becomes of paramount importance for conventional structures $[3,4,7$, 8 ], or structures that are equipped by passive control devices. Passive control devices are typically adopted within the framework of the design strategy based on supplementary energy dissipation. As an alternative, passive control devices can be used to substitute traditional dissipative zones, typically the beam ends $[5,6,9]$. Passive control devices are devices that do not require power to operate and

*Address correspondence to this author at the Technological Educational Institution of Athens, Department of Civil Engineering, Surveying and Geoinformatics, Ag. Spyridonos Str., P.O. 12210 Egaleo-Athens, Greece; Tel: +30-211-7059910; Fax: +30-210-5385858; E-mail: pnevma@teiath.gr are installed into the structure. Examples of passive devices are base isolation, tuned mass dampers (TMD), tuned liquid dampers (TLD), metallic yield dampers, viscous fluid dampers and friction dampers [10], [11]. They dissipate energy using the motion of the structure to produce relative movement within the control device or to alter the dynamic properties of the structure (damping, natural frequencies), so that the earthquake action will be minimized. Since they do not inject energy into the system, they are stable devices. Another advantage of such devices is their low maintenance requirements and the fact that they are unaffected by potential interruptions in power supply.

\section{Active Control}

Active control strategies have been developed in the 1990s, Soong [1], Housner, et al. [12] they operate by using external energy supplied by actuators to impart forces on the structure. The appropriate control action is determined based on measurements of the structural response. Active control devices include active-mass-damper (AMD), the active tendon system, the active bracing system and the active tuned mass damper. Active control devices require considerable amount of external power to operate actuators that supply a 


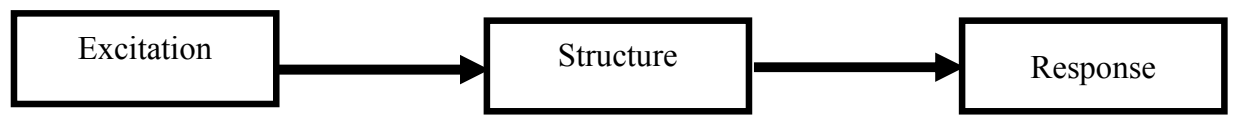

Fig. (1). Conventional structure and the response under the seismic excitation.

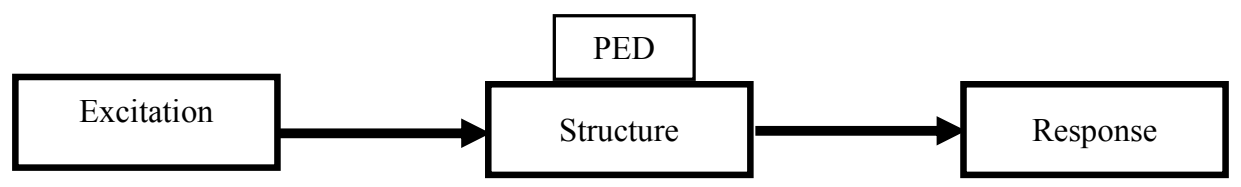

Fig. (2). Structure with passive energy dissipation devices (PED).

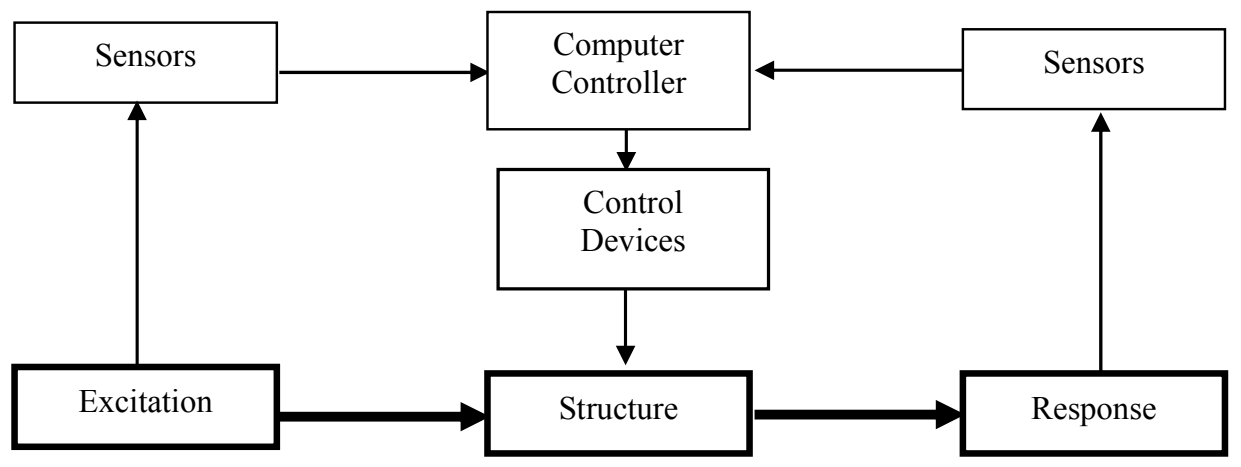

Fig. (3). Structure with active control devices.

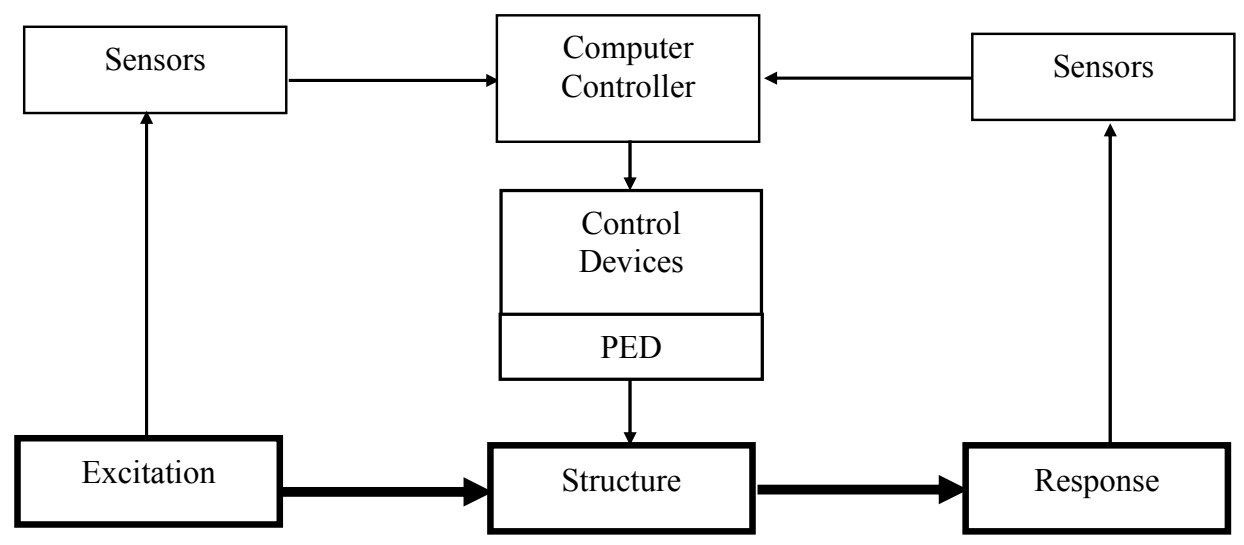

Fig. (4). Structure with semi-active control devices.

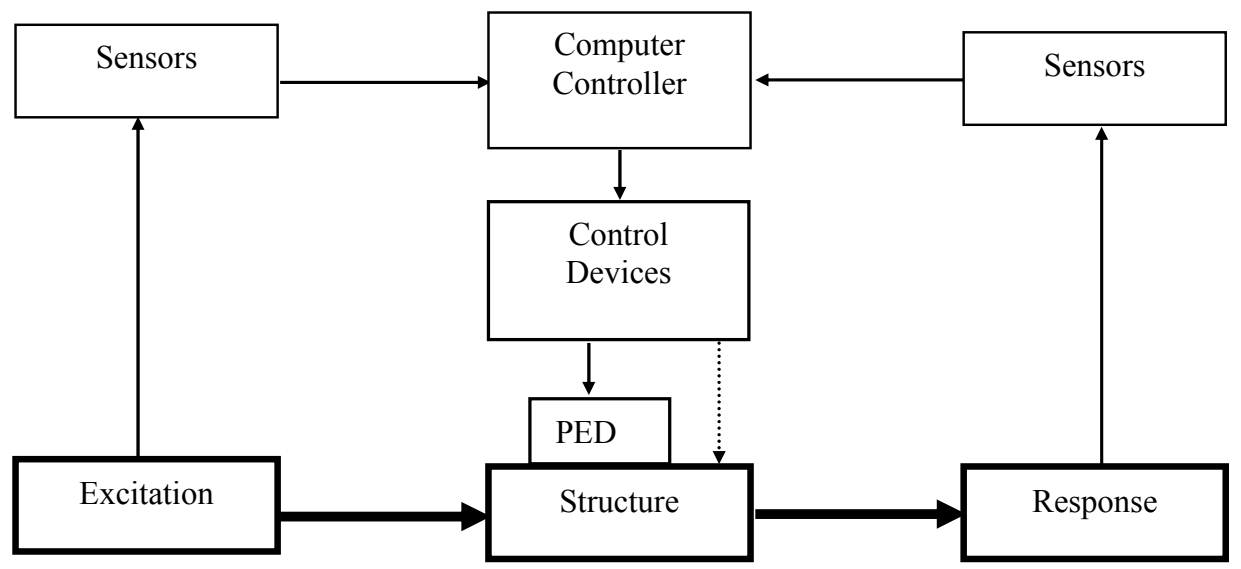

Fig. (5). Structure with hybrid control devices. 
control force to the structure. Such power may not always be available during seismic events. Another drawback is that due to their capacity to add energy to the system, they may destabilize it. Cost and maintenance of such systems is also significantly higher than that of passive devices. On the other hand, they are more effective than passive devices because of their ability to adapt to different loading conditions and to control different modes of vibration. Housner et al. [12] point out the importance of system integration in the design and development of active control systems. Not only is it necessary to consider the individual components of a control system, but the system as a whole must be understood, including the structure, control devices, sensors, and computer control system. Błachowski [13] use model based predictive control to reduce the vibration for guyed mast.

\section{Semi-Active Control}

Semi-active control devices offer the adaptability of active ones without requiring such high power, since external power is only used to change the device's properties, such as damping or stiffness, and not to generate a control force, Symans et al. [14]. In fact, many semi-active devices can operate on battery power, which is critical during seismic events, when the main power source to the structure may fail. Examples of such devices include variable-orifice fluid dampers, controllable friction devices, variable stiffness devices, controllable liquid dampers and controllable fluid dampers. A semi-active controllable fluid device is a combination of dampers with fluids that have the ability to reversibly change their viscosity. The two controllable fluids used in structural control devices are ElectroRheological (ER) and MagnetoRheological (MR) fluids. Other semi-active devices use the force generated by surface friction to dissipate energy in a structural system. Another semi-active control devices use the dynamic motion of a sloshing fluid or a column of fluid to reduce the response of a structure. These liquid dampers are the evolution of passive tuned sloshing dampers (TSD) and tuned liquid column dampers (TLCD). Semiactive tuned mass dampers are similar to TMDs, but with the capability of varying their level of damping. They are mainly used for wind vibration reduction. Variable-stiffness control devices have the ability to modify the structure's stiffness and therefore its natural frequency, to avoid resonant conditions. These systems have been studied by Kobori et al. [15] and Pnevmatikos and Gantes [16].

\section{Hybrid Control}

Hybrid control refers either to a combination of passive and active systems or, more commonly, to a combination of passive with semi-active systems, aiming at lowering the forces required by active or semi-active systems, respectively. One such device is the hybrid mass damper (HMD), which combines tuned mass dampers with active actuators. The actuator force is only used to increase efficiency and robustness to changes in structural dynamic characteristics. Also in the category of hybrid mass dampers is the activepassive composite tuned mass damper (APTMD) developed by Ohrui et al. [17] and named DUOX. Base isolation systems are passive systems and they do not have the ability to adapt and change their properties in different external excitation (for example, near or far fault excitation). With the addition of an active or semi-active control device to a base iso- lated structure, a higher level of performance can be achieved without a substantial increase in the cost. This thought has led to another type of hybrid control system, referred to as hybrid seismic isolation, consisting of active or semi active devices introduced in base-isolated structures. In addition, a semi-active friction-controllable fluid bearing has been employed in parallel with a seismic isolation system Feng et al. [18].

A state-of-the-art on knowledge needed to successfully implement an passive, active, hybrid or semi-active control system to a structure and several case studies showing their implementation and effectiveness to mitigate environmental forces such as wind or earthquakes are provided in literature [19], [20]. The structure and the control system in most cases are designed separately in buildings. The structure is design based on building codes and the control system is designed in order to minimize the deformation of the structure with control effort constrained. Cimellaro et al. [21] considered a design procedure based on interaction between the structure and the control system and simultaneous optimization design of both systems which is necessary in order to obtain the required performance with minimum cost. Over the past few decades various control algorithms and control devices have been developed, modified and investigated by various groups of researchers. The work of Yao [22], Housner et al. [12], Kobori et al. [23], Spenser et al. [24, 25], Yang [26], Renzi [28], Lu and Skelton [27], Soong [1] is representative. While many of these structural control strategies have been successfully applied, challenges pertaining to cost, reliance on external power and mechanical intricacy during the life of the structure have delayed their widespread use. In the work of Kurata et al. [29], the reliability from the point of view of health monitoring and fail safe function is discussed. There have been some attempts to connect the control forces with the design codes. Yang et al. [30] suggest the maximum control force to be a percentage of the building weight, while Cai et al. [31] give this force as a portion of the seismic force. Lee et al. [32] determine the upper limit of control force based on the response spectrum of the external earthquake.

In past years the design philosophy of new structures was to design a stiff structure with high strength to resist the earthquake in elastic range. After that the design philosophy moves one step further. Using the ductility of materials, structures were designed to resist lower level of earthquake forces but to have adequate plasticity to face the attack of destructive earthquakes. This drives to lighter and more economic structures compared to previous structures. However, the capacity design and the reinforcement details increase the cost. Taking into account the cost of repair and of retrofitting of structures, the design of ductile structures arise a lot of questions.

The proposed design procedure is based on the use of control devices which are installed to the structure and provide a reservoir of strength, stiffness or damping, necessary for preventing the structure from damage when the design earthquake will occur. Thus, the control system will drive the structure to behave in elastic range when attacked by the design earthquake and no damages will occur. As far as cost is concerned, it is possible to achieve substantial savings by avoiding retrofit of the structure during the life time and uti- 
lize these savings to install a control system. The different design philosophy stages of structures are shown in Fig. (6). Firstly, structures were designed to remain in elastic range when an earthquake is applied, Fig. (6a), then from the 80's until today, ductile structures which goes beyond the yield, formation of plastic hinges (damage) when the design earthquake occurs is the normal procedure, Fig. (6b) and finally structures equipped with control devices in order to behave linear and no damage occurs during the design earthquake Fig. (6c). A systematic procedure to achieve the above objective is proposed in this work.

\section{DESIGN PROCEDURE FOR STRUCTURES EQUIPPED WITH A CONTROL SYSTEM}

With the proposed methodology, the controlled structure is initially designed based on a design spectrum provided by the pertinent code (Eurocodes) with a specific level of ductility. The required control forces will take a portion of earthquake forces and are calculated as the difference between the forces obtained from the elastic spectrum and those obtained from the design spectrum. The maximum value of capacity of control devices is compared with the required control force. If the capacity of the controlled devices is higher than the required control force then the control devices are accepted and installed to the structure. If the capacity is lower than the required control force then a control device with higher capacity should be chosen or more devices per each floor should be installed. In the case where the maximum available control device capacity is lower than the required control force or there is a limitation to the number of control devices, then an iterative procedure is used based on a scale factor, $\alpha$, that reduces the elastic response spectrum. The structure is redesigned based on the spectrum reduced by scale factor, a, and then the devices are installed to the structure. The flow chart of the procedure is shown in Fig. (7) with solid line.

From the seismic forces and the maximum capacity of the control device a scale factor $\alpha$ is obtained and applied to reduce the elastic spectrum. Knowing the mass and initial stiffness of the structure, the eigenmodes $\Phi_{i}$, the eigenperiods $T_{i}$ or the eigenfrequencies $f_{i}$ and the corresponding damping ratios $\xi_{\mathrm{i}}$ of the uncontrolled system are obtained from the solution of the following eigenvalue problem Chopra [33]:

$$
\begin{aligned}
& {\left[\mathbf{K}-\omega^{2} \mathbf{M}\right]_{\mathrm{nxn}} \Phi=0 \Rightarrow\left|\mathbf{K}-\omega^{2} \mathbf{M}\right|=0 \Rightarrow\left\{\begin{array}{c}
\Phi_{1}, \Phi_{2}, \ldots, \Phi_{\mathrm{n}} \\
\omega_{1}, \omega_{2}, \ldots \omega_{\mathrm{n}}
\end{array} \Rightarrow\right.} \\
& \mathrm{T}_{\mathrm{i}}=\frac{2 \pi}{\omega_{\mathrm{i}}}, \quad \mathrm{f}_{\mathrm{i}}=\frac{\omega_{\mathrm{i}}}{2 \pi}, \quad \mathrm{i}=0, \ldots, \mathrm{n}-1 \\
& \mathbf{C}_{\mathrm{n}}=\Phi_{\mathrm{n}}^{\mathrm{T}} \mathbf{C} \Phi_{\mathrm{n}} \\
& \mathbf{M}_{\mathrm{n}}=\Phi_{\mathrm{n}}^{\mathrm{T}} \mathbf{M} \Phi_{\mathrm{n}} \\
& \xi_{\mathrm{i}}=2 \mathbf{C}_{\mathrm{n}} \mathbf{M}_{\mathrm{n}} \omega_{\mathrm{n}}
\end{aligned}
$$

The participation factor $\psi_{\mathrm{i}}$, and seismic forces $\mathbf{F}_{\mathrm{q}, \mathrm{i}}$ for the $i^{\text {th }}$ eigenmode are given as:

$$
\begin{aligned}
& \psi_{\mathrm{i}}=\frac{\boldsymbol{\Phi}_{\mathrm{i}}^{\mathrm{T}} \mathbf{M E}}{\boldsymbol{\Phi}_{\mathrm{i}}^{\mathrm{T}} \mathbf{M} \boldsymbol{\Phi}_{\mathrm{i}}}, \quad \mathrm{i}=1, \ldots, \mathrm{n} \\
& \mathbf{F}_{\mathrm{q}, \mathrm{i}}=\mathbf{M} \boldsymbol{\Phi}_{\mathrm{i}} \psi_{\mathrm{i}} \mathrm{S}_{\mathrm{a}, \mathrm{i}}\left(\mathrm{T}_{\mathrm{i}}, \xi_{\mathrm{i}}\right), \quad \mathrm{i}=1, \ldots, \mathrm{n}
\end{aligned}
$$

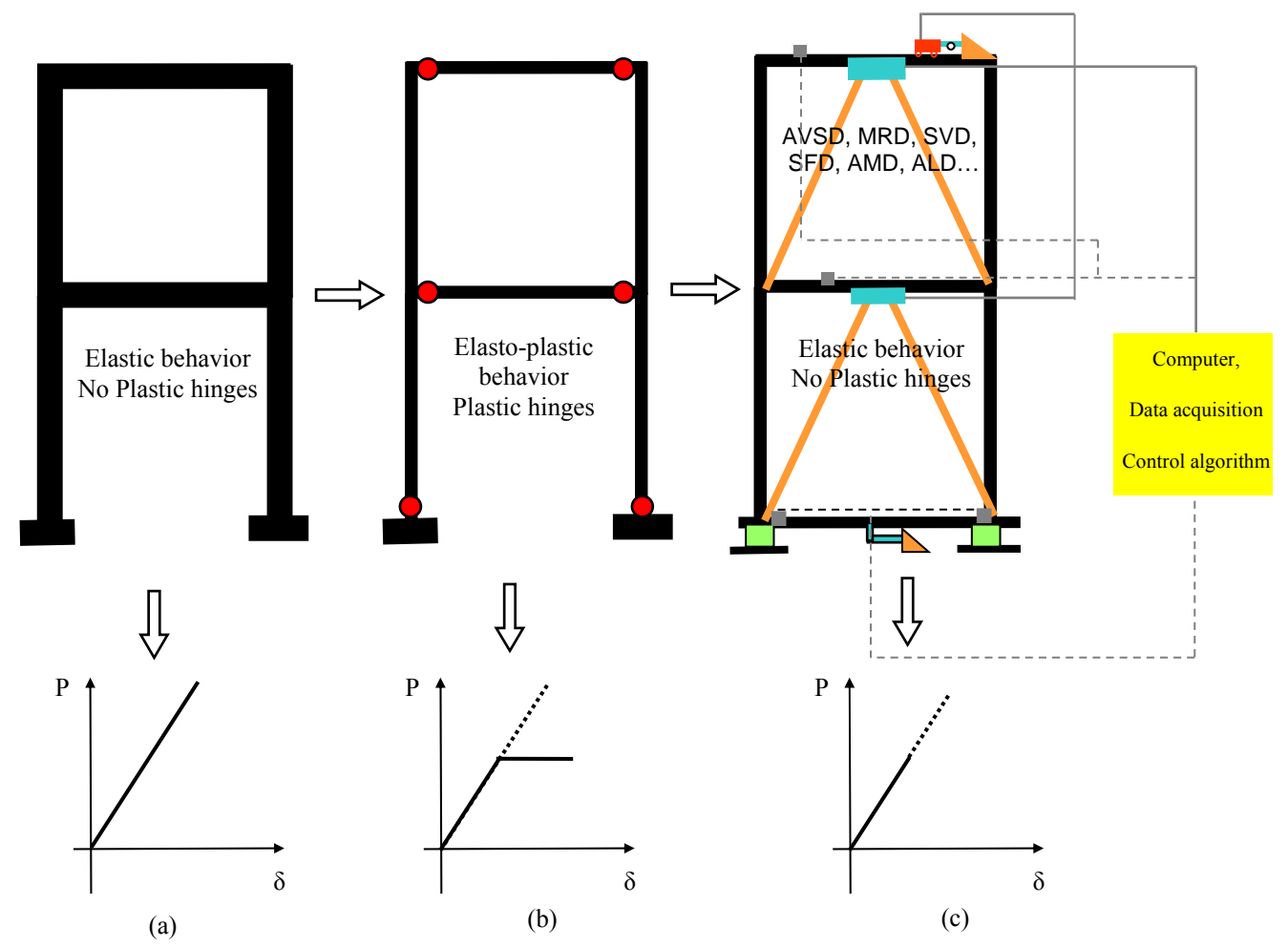

Fig. (6). Different alternatives of design philosophy of structures. 


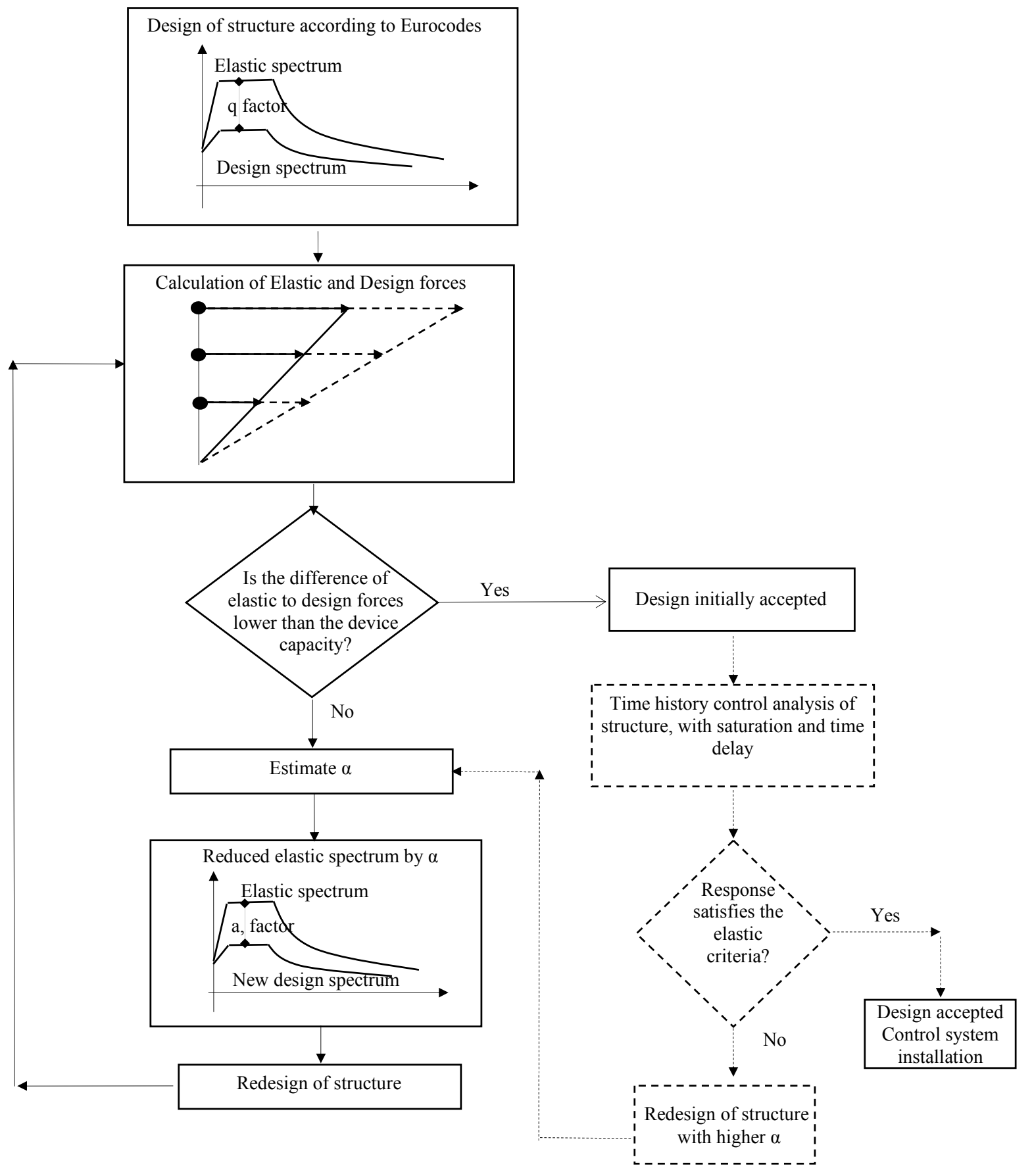

Fig. (7). The flow chart of the proposed design procedure.

where $\mathbf{E}$ is the direction matrix for the earthquake and $\mathrm{S}_{\mathrm{a}, \mathrm{i}}\left(\mathrm{T}_{\mathrm{i}}, \xi_{\mathrm{i}}\right)$ is the spectral acceleration. The maximum seismic forces $\mathbf{F}_{\mathrm{q}}$ for each degree of freedom are obtained combining with Square Root of Sum Squares method (SRSS) the seismic forces from each eigenmode, thus:

$\mathbf{F}_{\mathrm{q}}=\sqrt{\sum_{\mathrm{i}}^{\mathrm{n}} \mathbf{F}_{\mathrm{q}, \mathrm{i}}^{2}}$

If $\mathrm{F}_{\mathrm{d}, \max }$ is the maximum control device capacity (maximum possible control force), then the maximum control force that can be applied on the structure by control devices is:
$\mathbf{F}_{\mathrm{d} \text {,max }}=\mathbf{E}_{\mathrm{f}} \mathrm{F}_{\mathrm{d}, \text { max }}$

where $\mathbf{E}_{\mathrm{f}}$ is the location matrix for the control devices on the structure. The matrix $\mathbf{E}_{\mathrm{f}}$ is provided in the example section and for the specific control device configuration is shown in Fig. (8). The remaining maximum seismic forces which are applied to the structure equipped by control devices are:

$\mathbf{F}_{\mathrm{q}, \text { new }}=\left\{\begin{array}{ccc}\mathbf{F}_{\mathrm{q}}-\operatorname{sign}\left(\mathbf{F}_{\mathrm{q}}\right) \mathbf{F}_{\mathrm{d}, \text { max }} & \text { if } & \left|\mathbf{F}_{\mathrm{q}}\right| \geq \mathbf{F}_{\mathrm{d}, \text { max }} \\ 0 & \text { if } & \left|\mathbf{F}_{\mathrm{q}}\right|<\mathbf{F}_{\mathrm{d}, \text { max }}\end{array}\right.$ 


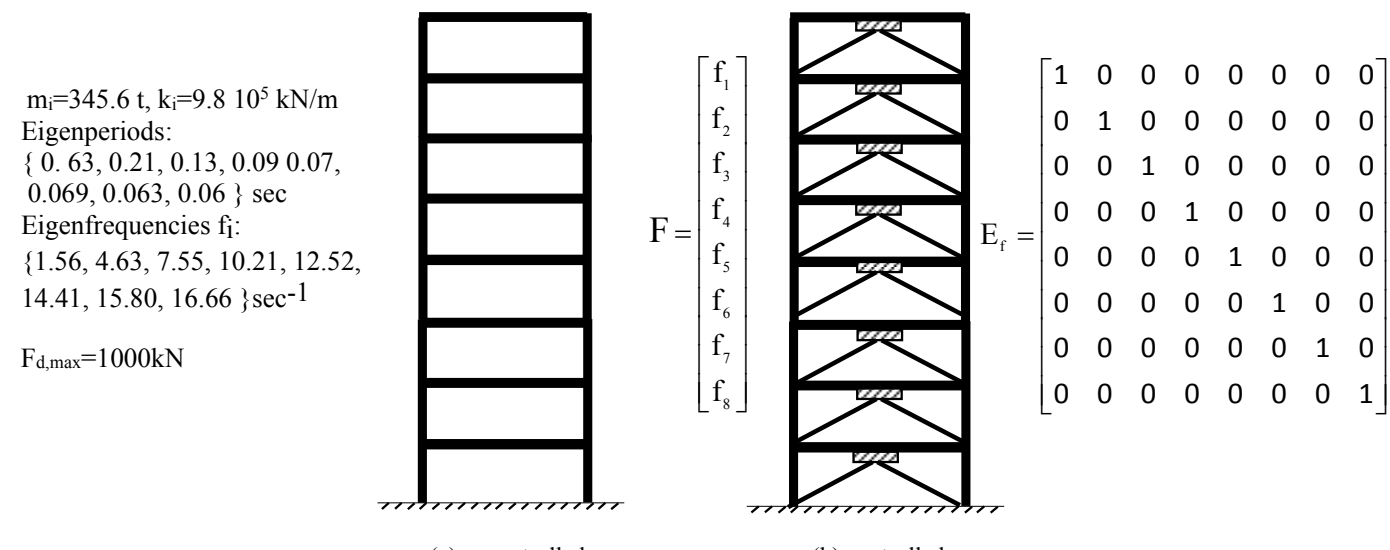

(a) uncontrolled

(b) controlled

Fig. (8). The dynamic characteristic and the control scheme of building.

These forces correspond to a reduced spectral acceleration. Making the assumption that the participation factor, $\psi_{i}$, is the same for the controlled and the uncontrolled structure, using equation (4), the new spectral acceleration $S_{d, i, n e w}\left(T_{i}\right.$, $\xi_{\mathrm{i}}$ ), corresponding to new seismic forces, can be obtained:

$\mathrm{S}_{\mathrm{a}, \mathrm{in \text {new }}}\left(\mathrm{T}_{\mathrm{i}}, \xi_{\mathrm{i}}\right)=\frac{\left(\mathbf{M} \boldsymbol{\Phi}_{\mathrm{i}}\right)^{-1} \mathbf{F}_{\mathrm{q}, \text { new }, \mathrm{i}}}{\psi_{\mathrm{i}}}, \quad \mathrm{i}=1, \ldots, \mathrm{n}$

The reduction factor, $\alpha$, can be obtained by dividing the new spectral acceleration $\Phi_{\mathrm{d}, \mathrm{inew}}\left(\mathrm{T}_{\mathrm{i}}, \xi_{\mathrm{i}}\right)$ by the corresponding initial one:

$\alpha_{i}=\frac{S_{a, i n e w}\left(T_{i}, \xi_{i}\right)}{S_{a, i}\left(T_{i}, \xi_{i}\right)}, \quad i=1, \ldots, n$

The elastic spectrum is scaled using the maximum value of $\alpha_{\mathrm{i}}$ and the structure is redesigned based on the reduced spectrum.

$\alpha=\max \left(\alpha_{\mathrm{i}}\right)$

In order to ensure a linear behavior of the structure, dynamic control analysis is performed for a range of earthquakes (high and low frequency characteristics), with saturation control and time delay. If the response satisfies the elastic criteria (for example inter-story drift ratio below a limit value), then the value of $\alpha$ is accepted, otherwise it is slightly increased and the above procedure is repeated. The flow chart of this procedure is shown in Fig. (7) with dashed line.

The equation of motion of a controlled structural system with $\mathrm{n}$ degrees of freedom subjected to an earthquake excitation $\mathrm{a}_{\mathrm{g}}$ is:

$$
\mathbf{M U}+\mathbf{C}_{\text {new }} \dot{\mathbf{U}}+\mathbf{K}_{\text {new }} \mathbf{U}=-\mathbf{M E a}_{\mathrm{g}}+\mathbf{E}_{\mathrm{f}} \mathbf{F}
$$

where $\mathbf{M}, \mathbf{C}$ denote the mass and damping matrices of the structure, respectively, $\mathbf{K}_{\text {new }}$ is the new stiffness matrix of the redesigned structure, and $\mathbf{F}$ is the control force matrix. In the state space approach the above equation (11) can be written as follows:

$$
\dot{\mathbf{X}}=\mathbf{A X}+\underset{\mathrm{g} g}{\mathbf{B} \text { a }}+\mathbf{B} \mathbf{F}
$$

The matrixes $\mathbf{X}, \mathbf{A}, \mathbf{B}_{\mathbf{g}}, \mathbf{B}_{\mathbf{f}}$ are given by

$$
\begin{aligned}
& \mathbf{X}=\left[\begin{array}{c}
\mathbf{U} \\
\dot{\mathbf{U}}
\end{array}\right]_{2 n \times 1}, \mathbf{A}=\left[\begin{array}{cc}
\mathbf{0} & \mathbf{I} \\
-\mathbf{M}^{-1} \mathbf{K}_{\text {new }} & -\mathbf{M}^{-1} \mathbf{C}_{\text {new }}
\end{array}\right]_{2 n 22 n}, \\
& \mathbf{B}_{\mathrm{g}}=\left[\begin{array}{c}
\mathbf{0} \\
-\mathbf{E}
\end{array}\right]_{2 n \times 1}, \quad \mathbf{B}_{\mathrm{f}}=\left[\begin{array}{c}
\mathbf{0} \\
\mathbf{M}^{-1} \mathbf{E}_{\mathrm{f}}
\end{array}\right]_{2 n \times 1}
\end{aligned}
$$

It is assumed that the control force $\mathbf{F}$ is determined by linear state feedback:

$$
\mathbf{F}=-\mathbf{G}_{1} \mathbf{U}-\mathbf{G}_{2} \dot{\mathbf{U}}=-\left[\begin{array}{ll}
\mathbf{G}_{1} & \mathbf{G}_{2}
\end{array}\right]\left[\begin{array}{c}
\mathbf{U} \\
\dot{\mathbf{U}}
\end{array}\right]=-\mathbf{G X}
$$

$\mathbf{G}$ is the gain matrix, which will be calculated according to the desired poles of the controlled system. The eigenvalues or poles of the uncontrolled system are given by:

$$
\lambda_{\mathrm{i}}=-\omega_{\mathrm{i}} \pm \mathrm{j} \omega_{\mathrm{i}} \sqrt{1-\xi_{\mathrm{i}}^{2}}, \quad \mathrm{j}=\sqrt{-1}
$$

where $\omega_{\mathrm{i}}$ and $\xi_{\mathrm{i}}$ are the eigenfrequencies and the damping ratio, respectively, which are obtained from the solution of the eigenvalue problem. If a state space formulation is adopted, then these eigenvalues are obtained directly from the eigenvalues of matrix $\mathbf{A}$ :

$$
\operatorname{det}[\lambda \mathbf{I}-\mathbf{A}]=0 \rightarrow \lambda_{\mathrm{i}}=\alpha_{\mathrm{i}} \pm \mathrm{j} \beta_{\mathrm{i}}
$$

If the response obtained for the controlled system satisfies the design criteria, then the value of scale factor, $\alpha$, is accepted. In this work a representative design criterion was used requiring that the story drift does not exceed $\mathrm{h} / 300$ (where $h$ is the story height). This value does not cause member yielding. In a similar way, additional design criteria concerning the section rotation at the end of length of structural member, (chord angle) or strength of structural members can be used. The above procedure was tested for a number of numerical simulations and some representative examples are presented next.

\section{NUMERICAL EXAMPLES AND DISCUSSIONS}

The proposed approach is demonstrated by means of numerical examples where an eight-story building, shown in Fig. (8) and described in [34], is analyzed. Initially the elastic and design spectrum are calculated according to Eurocode 8 (EC8) seismic code [35], with the parameters shown in Fig. (9). It is worth to mention that, in the spectra proposed 
Max ground acceleration $\mathrm{agR}_{\mathrm{gR}}=0.24 \mathrm{~g}$ Importance factor $\gamma_{1}=1$

Correction coefficient for damping $\neq 5 \%, \mathrm{n}=1$ for $\zeta=0.05$ Soil category $\mathrm{B}, \mathrm{T}_{\mathrm{B}}=0.15, \mathrm{~T}_{\mathrm{C}}=0.5, \mathrm{~T}_{\mathrm{D}}=2.5, \mathrm{~S}=1.20$ Behavior factor $\mathrm{q}=3$

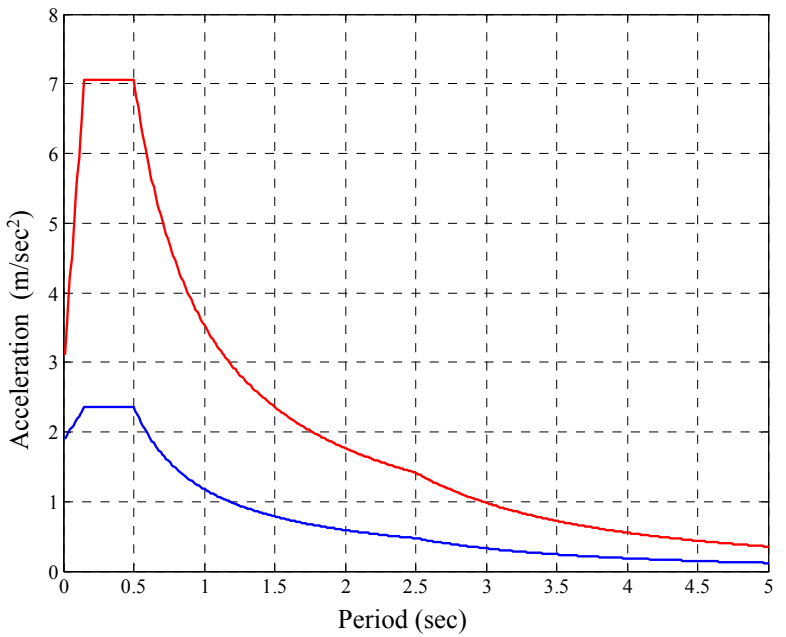

Fig. (9). Code parameters and the elastic (dash line) and design spectrum (solid line).
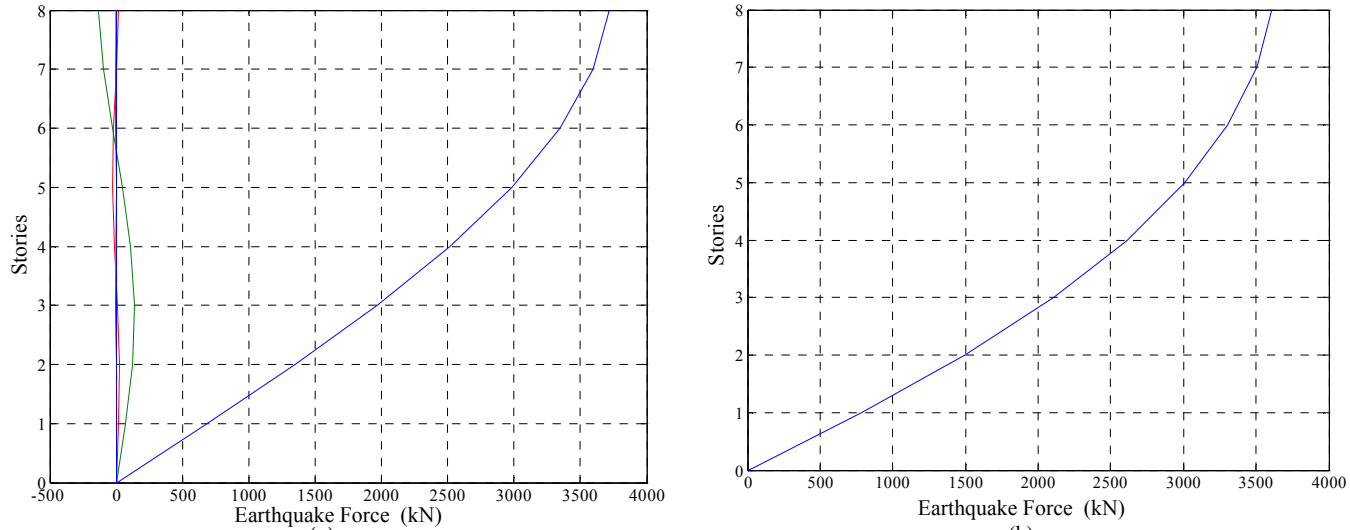

(b)
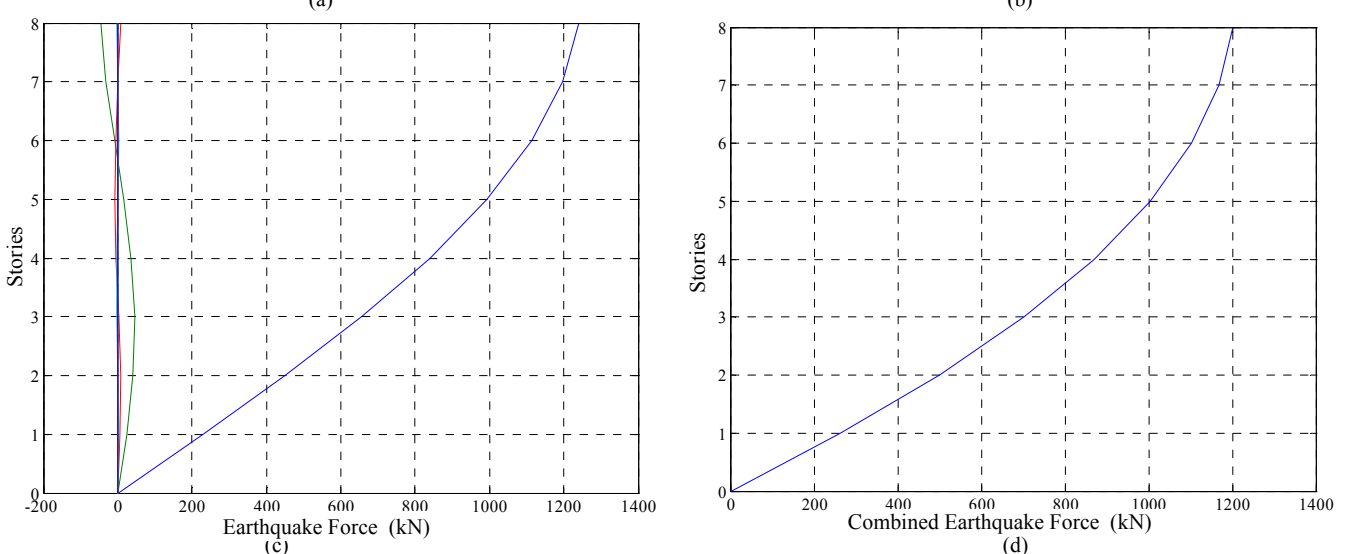

Fig. (10). Seismic forces from elastic spectrum for each eigenmode (a); and their combinations (b); and seismic forces from design spectrum for each eigenmode (c); and their combinations (d).

by EC8, at zero period the elastic and design spectrum do not coincide. Specifically, the value of acceleration from the design spectrum at zero period is $2 / 3$ to the acceleration from the elastic spectrum at zero period.

Based on such spectra and on the dynamic characteristics of the building the seismic forces $\mathrm{F}_{\mathrm{q}, \mathrm{i}}$ for each eigenmode and their combination are calculated both for elastic and design spectrum and are shown in Fig. (10). The seismic forces which are obtained from elastic and design spectrum and their differences are shown in Fig. (11a). Assuming that the control devices are installed at each floor as shown in Fig. (8b) and the maximum capacity is $1000 \mathrm{kN}$, following the proposed procedure the scale factor $\alpha$ is calculated to be equal to 0.49 so that the equivalent reduction from elastic spectrum, $1-\alpha$, is equal to $51 \%$. The elastic and design spectra and the spectrum reduced by $51 \%$ from the elastic one, for which the structure will be redesigned, are illustrated in Fig. (11b). 


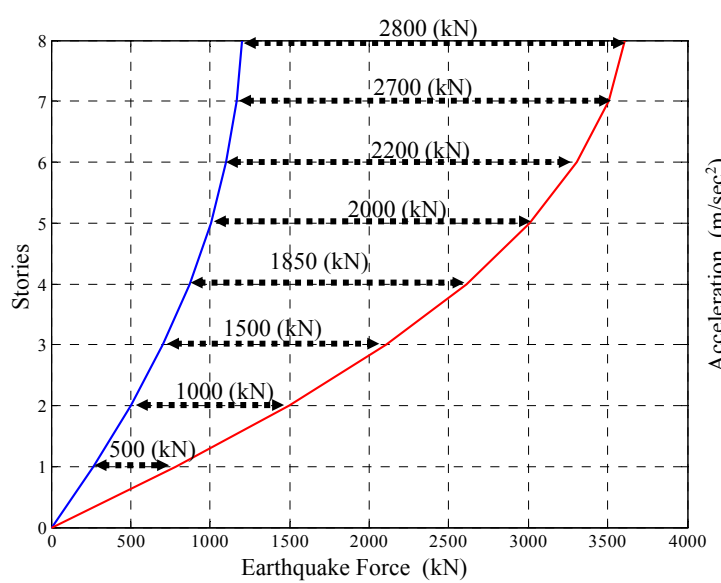

(a)

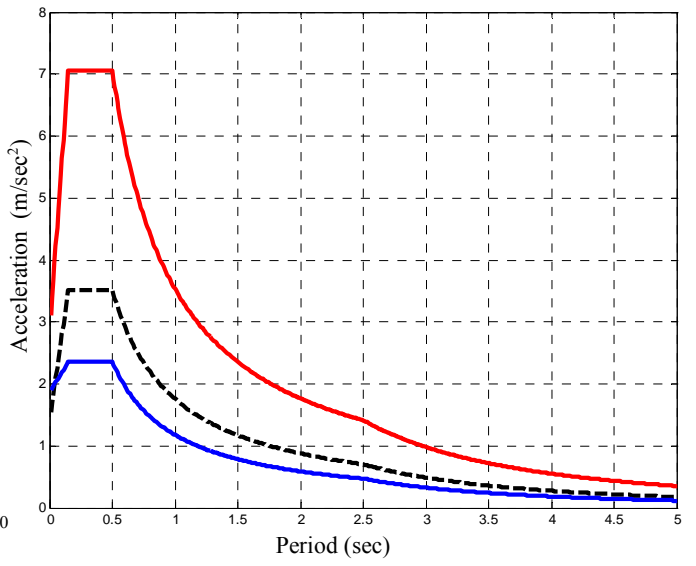

(b)

Fig. (11). The difference between elastic and design forces for each story, (a); the elastic and design spectrum, according to EC8, and the reduced elastic spectrum (dash line) for the structure with control devices, (b).

In order to ensure that the structure remain in the elastic range after redesigning, dynamic time history control analysis, with saturation control and time delay, for a wide range of earthquakes should be performed. The numerical simulations were performed in Simulink toolbox of Matlab software [36]. The numerical simulation of the control scheme is described in Fig. (12). The maximum and the root mean square (rms) values from the response of the system subjected to Athens earthquake 1999 are shown in Table 1. The rms values were calculated in order to see to what extent the system performs near the maximum values. The earthquake was scaled with a factor equal to 1.45 so that the response spectrum matches the elastic spectrum at the first period of the structure to give the same spectral acceleration. From Table $\mathbf{1}$ it is seen that full compensation of the displacements was achieved. This is due to the fact that one control force was used for each degree of freedom. The acceleration is equal to the external signal and the building is like executing a rigid body motion. The control forces are all the same, with a maximum value equals to $880 \mathrm{kN}$ and rms value equals to $120 \mathrm{kN}$, because the mass of each story is the same. The storey drift between the floors not exceeded the limit value $\mathrm{h} / 300=10 \mathrm{~mm}$. Time history of displacement and the acceleration from $8^{\text {th }}$ floor for the controlled and uncontrolled structure is shown in Fig. (13). Comparison of the root mean square (rms) values to the maximum response values proved that the control system helps the structure not only to reduce the maximum response (displacements and accelerations) and keep it in elastic range, but also to perform at much lower level than the maximum response values.

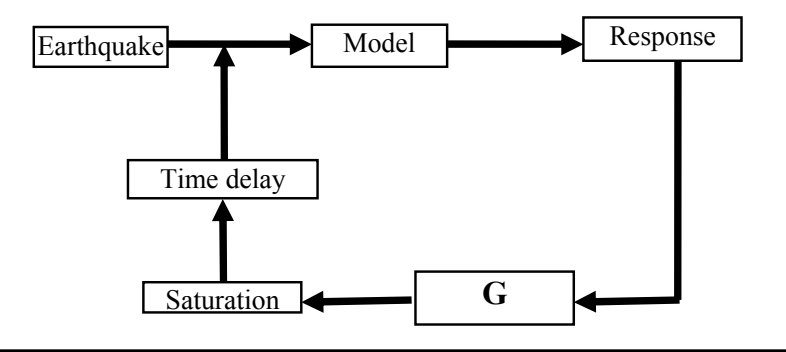

Fig. (12). Model and control scheme in Simuling toolbox.
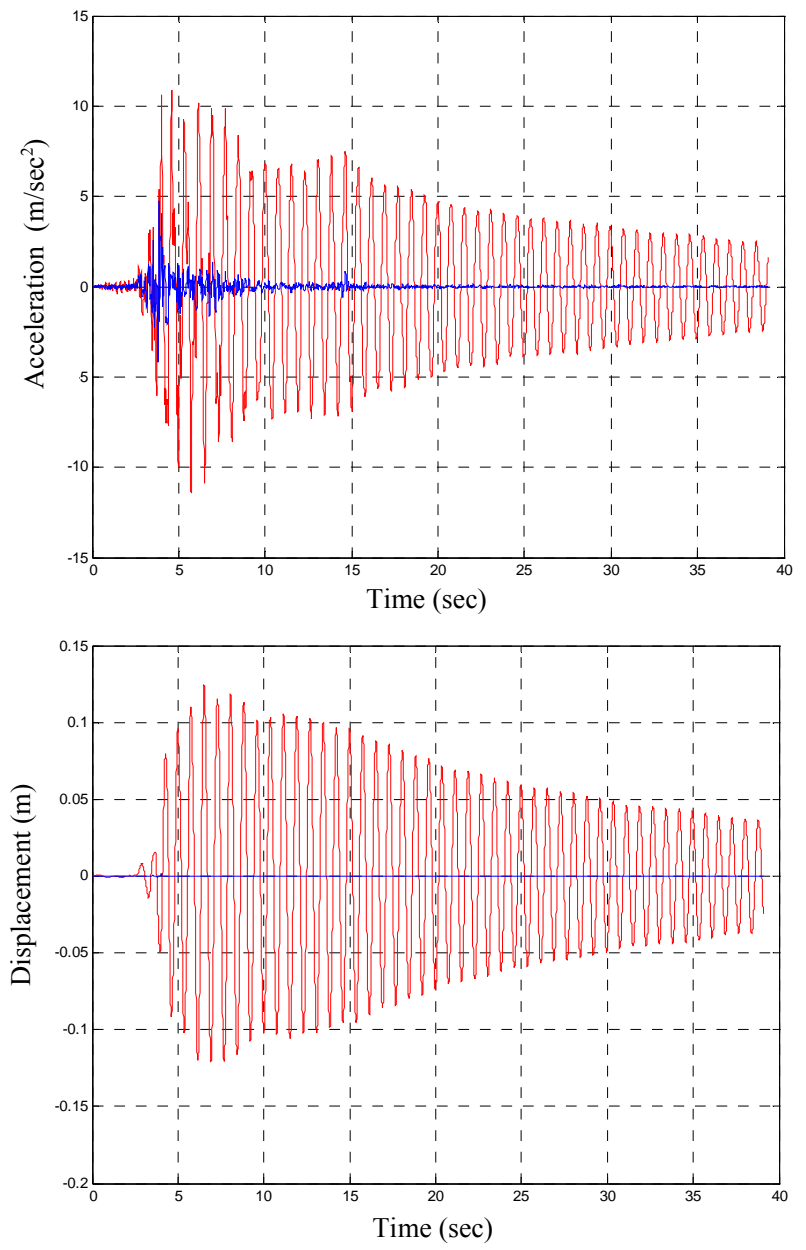

Fig. (13). Displacement and the acceleration from $8^{\text {th }}$ floor for the controlled and uncontrolled structure.

\section{SUMMARY AND CONCLUSION}

A procedure to design a new structure equipped with control devices is described. The structure is designed based on a reduced design spectrum. A scale factor, $\alpha$, which multiplies the elastic spectrum and produces a reduced design 
Table 1. Response and control forces of the controlled structure subjected to Athens 1999 earthquake.

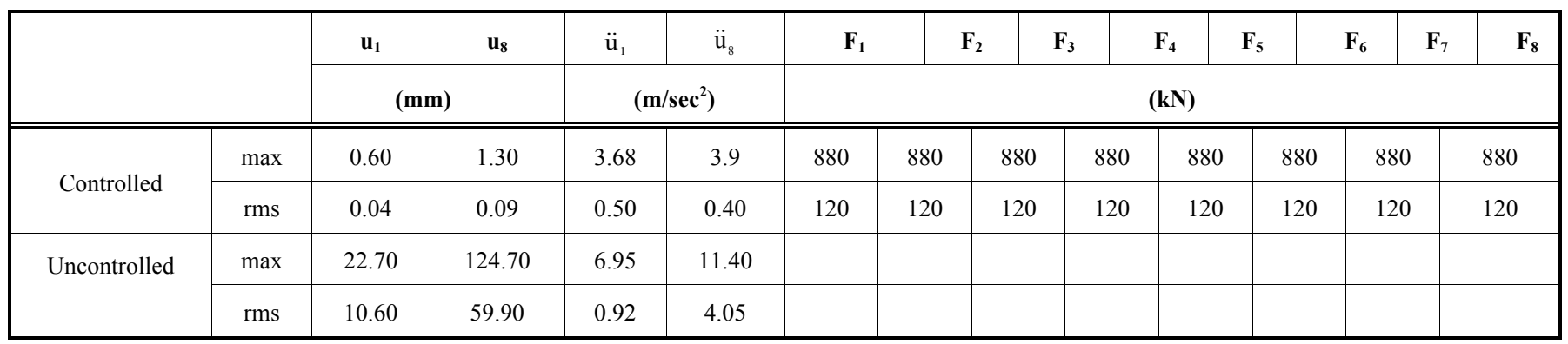

spectrum is proposed. The design philosophy is that one part of seismic forces is taken by the control devices and the remaining part of earthquake forces is resisted by the structure which is working in elastic range. The numerical results indicate that reduction of the spectrum can be achieved using control devices. The cost of repairing the post earthquake damages of an uncontrolled structure can be considered as a motivation to install a control system which will keep the structure under its yield limit. If control devices are installed at every degree of freedom, then full complete compensation of the relative displacements can be achieved. The control system is accepted if the results obtained from the dynamic control analysis keeps the response of the structure under the elastic limit values. Design parameters could be the interstory drifts which shouldn't exceed a specific value that causes yielding of the structural members or do not exceed a value which would cause serviceability problems. Other design parameters could be the internal forces such as moments or shear forces which shouldn't be higher than the yield capacity of the member.

The proposed procedure was applied to an $8^{\text {th }}$ story building and the numerical results have shown the effectiveness of the procedure. The control system helps the structure not only to reduce the maximum response (displacements and accelerations) and keep it in elastic range, but also to perform at much lower level than the maximum response values. The proposed design procedure of control structure seems promising. However, additional experimental and analytical studies dealing with 3D space frames are needed before its practical application.

\section{CONFLICT OF INTEREST}

The authors confirm that this article content has no conflict of interest.

\section{ACKNOWLEDGEMENTS}

Declared none.

\section{REFERENCES}

[1] T.T. Soong, Active structural control: Theory and practice. London/New York: Longman Scientific and Technical/Wiley, 1990.

[2] T.T. Soong, and B.F Jr Spencer, "Supplemental energy dissipation: state-of-the-art and state-of-the practice, Engineering Structures, vol. 24 , pp. 243-59, 2002.

[3] A. Longo, R. Montuori, and V. Piluso "Plastic design of seismic resistant V-braced frames", Journal of Earthquake Engineering, vol. 12 , no. 8, pp.1246-66, 2008.
[4] A. Longo, R. Montuori, and V. Piluso, "Failure mode control of Xbraced frames under seismic actions" Journal of Earthquake Engineering, vol. 12, no. 5, pp. 728-759, 2008.

[5] A. Longo, R. Montuori, V. Piluso, "Theory of plastic mechanism control of dissipative truss moment frames", Engineering Structures, vol. 37, pp. 63-75, 2012.

[6] A. Longo, R. Montuori, and V. Piluso "Failure mode control and seismic response of dissipative truss moment frames", Journal of Structural Engineering, vol. 138, no. 11, pp.1388-97, 2012.

[7] R. Montuori, E. Nastri, and V. Piluso, "Theory of plastic mechanism control for eccentrically braced frames with inverted Yscheme", Journal of Constructional Steel Research, vol. 92, pp. 122-35, 2014.

[8] F.M. Mazzolani, and V. Piluso, "Plastic design of seismic resistant steel frames", Earthquake engineering and structural dynamics, vol. 26, no. 2, pp. 167-91, 1997.

[9] V. Piluso, R. Montuori, and M. Troisi, "Innovative structural details in MR-frames for free from damage structures", Mechanics Research Communications, vol. 58, pp.146-56, 2014.

[10] R. Montuori, E. Nastri, and V. Piluso, "Theory of plastic mechanism control for the seismic design of braced frames equipped with friction dampers", Mechanics Research Communications, vol. 58, pp. 112-23, 2014.

[11] G.D. Hatzigeorgiou, and N.G. Pnevmatikos, "Maximum damping forces for structures with viscous dampers under near-source earthquakes”, Engineering Structures, vol. 68, pp.1-13, 2014.

[12] G. Housner, L. Bergman, T. Caughey, A. Chassiakos, R. Claus, S. Masri, R. Skelton, T. Soong, B. Spencer, and J. Yao, "Structural Control: Past, Present, and Future", Journal of Engineering Mechanics, vol. 123, 9, pp. 897-971, 1997.

[13] B.D. Błachowski, "Model based predictive control for guyed mast vibration", Journal of Theoretical and Applied Mechanics, vol. 45, 2, pp. 405-23, 2007.

[14] M.D. Symans, M.C. Constantinou, D.P. Taylor, and K.D. Garnujost, "Semi-active fluid viscous dampers for seismic response control", In: Proceedings of $1^{\text {st }}$ World Conference on Structural Control, Los Angeles, CA, 1994, pp. 3-12.

[15] T. Kobori, M. Takahashi, T. Nasu, N. Niwa, and K. Ogasawara, "Seismic response controlled structure with active variable stiffness system", Earthquake Engineering and Structural Dynamics, vol. 22, pp. 925-41, 1993.

[16] N. G. Pnevmatikos, and C. J. Gantes, "Design and control algorithm for structures equipped with active variable stiffness devices", Journal of Structural Control and Health Monitoring, vol.17, 6, pp. 591-613, 2010.

[17] S. Ohrui, T. Kobori, M. Sakamoto, N. Koshika, I. Nishimura, K. Sasaki, A. Kondo, and I. Fukushima, "Development of activepassive composite tuned mass damper and an application to the high rise building" In: Proceedings of the $1^{\text {st }}$ World Conference on Structural Control, 1994, pp.100-9.

[18] M.Q. Feng, and M. Shinozuka, Experimental and analytical study of a hybrid isolation system using friction controllable sliding bearings, Report No 92-0009, National center for earthquake engineering Research, Buffalo, NY. 1992

[19] S. Y. Chu, T. T. Soong, and A. M. Reinhorn, Active, Hybrid, and Semi-active Structural Control: A Design and Implementation Handbook, John Wiley and Sons Ltd, 2005, ISBN: 978-0-47001352-6. 
[20] F. Casciati, G. Magonette, and F. Marazzi, Technology of Semiactive Devices and Applications in Vibration Mitigation, John Wiley and Sons Ltd, 2006, ISBN: 978-0-470-02289-4.

[21] G.P. Cimellaro, T. T. Soong, and A.M. Reinhorn, "Optimal integrated design of controlled structures", In: Proceedings of $14^{\text {th }}$ World Conference on Earthquake Engineering, October 12-17, 2008, Beijing, China.

[22] J.T.P. Yao, "Concepts of structural control”, Journal of structural engineering ASCE, vol. 98, pp.1567-74, 1972.

[23] T. Kobori, "Future perspective of structural control in earthquake engineering", In: Proceedings of $12^{\text {th }}$ World Conf. on Earthquake Engineering, Auckland, New Zealand, 2000, Article No 2841.

[24] B.F. Spencer, S.J. Dyke, and H.S. Deoskar, "Benchmark problem in structural control Part I: Active mass driver system," In: Proceedings of ASCE Structures Congress, 1997, Portland.

[25] B.F. Spencer, S.J. Dyke, and H.S. Deoskar, "Benchmark problem in structural control Part II: Active tendon system," In: Proceedings of ASCE Structures Congress, 1997, Portland.

[26] J.N. Yang, "Application of optimal control theory to civil engineering structures", Journal of Engineering Mechanics Division ASCE, vol. 101, pp. 819-38, 1975.

[27] J. Lu, and R. Skelton, "Covariance control using closed-loop modeling for structures", Earthquake Engineering and Structural Dynamics, vol. 27, pp. 1367-83, 1998.
[28] E. Renzi, and G. Serino, "Testing and modeling a semi-actively controlled steel frame structure equipped with MR dampers", Structural Control Health Monitoring, vol. 11, pp.189-221, 2004.

[29] N. Kurata, and T. Kobori, "Reliability of applied semiactive structural control system," Journal of Structural Engineering, vol. 129, pp. 914-21, 2003.

[30] J.N. Yang, J.C. Wu, A.K. Agrawal, and S.Y. Hsu, "Sliding mode control of seismically excited linear structures", Journal of Engineering Mechanics, ASCE, vol. 121, pp.1386-90, 1995.

[31] G.P. Cai, J.Z. Huang, F. Sun, and C. Wang, "Modified sliding mode bang-bang control for seismically excited linear structure", Earthquake Engineering and Structural Dynamic, vol. 29, pp.164757, 1997.

[32] S.H. Lee, K.W. Min, Y.C. Lee, and L. Chung, "Improved design of sliding mode control for civil structures with saturation problem", Earthquake Engineering and Structural Dynamics, vol. 33, pp.1147-64, 2004.

[33] A.K. Chopra, Dynamics of Structures: Theory and Applications to Earthquake Engineering, Prentice Hall, Upper Saddle River, New Jersey, 1990.

[34] J.N. Yang, J.C. Wu, A.K. Agrawal, and S.Y. Hsu, "Sliding mode control for non linear and hysteretic structures", Journal of Engineering Mechanics ASCE, vol. 121, pp.1330-9, 1995.

[35] EN 1998 Eurocode 8: Design of structures for earthquake resistance.

[36] MATLAB. The Math Works Inc. Natick, Massachusetts, 1994.

Received: June 21, 2014

Revised: September 15, 2014

Accepted: September 30, 2014

(C) Pnevmatikos and Hatzigeorgiou; Licensee Bentham Open.

This is an open access article licensed under the terms of the Creative Commons Attribution Non-Commercial License (http://creativecommons.org/licenses/by-nc/3.0/) which permits unrestricted, non-commercial use, distribution and reproduction in any medium, provided the work is properly cited. 